\title{
Comparative Study of Areca Fiber Reinforced Polyester Composites and Plywood
}

\author{
Md. Zahidul Islam \\ Assistant Professor, Department of Yarn Engineering, \\ Bangladesh University of Textiles, Dhaka, Bangladesh \\ A.N.M. Masudur Rahman \\ Lecturer, Department of Fabric Engineering, \\ Bangladesh University of Textiles, Dhaka, Bangladesh \\ Hosne Ara Begum \\ Professor, Department of Yarn Engineering, \\ Bangladesh University of Textiles, Dhaka, Bangladesh
}

Doi: 10.19044/esj.2018.v14n30p98 URL:http://dx.doi.org/10.19044/esj.2018.v14n30p98

\begin{abstract}
In this study, the mechanical properties of the composites made of areca fibers as reinforcing agent with polyester matrix were evaluated. Both untreated and treated (mercerized) fibers were used to fabricate composites and the mechanical properties such as tensile strength (TS), tensile modulus (TM), flexural strength (FS), flexural modulus (FM) and impact strength (IS) of the composites were examined. Composites were manufactured by means of hand lay-up technique with varying fiber content (5 and 10\%). Mechanical properties of plywood were also tested and compared with the composites. It was found that areca fiber composites showed significant improved mechanical properties than plywood. Among the composite materials $10 \%$ fiber loading presented higher mechanical properties than 5\% fiber content and the treated fiber composites exhibited enhanced mechanical properties than the untreated fiber composites due to strong interfacial bonding between fiber and matrix. In addition, water uptake test was performed and specifies that areca composites absorbed very much lower amount of water than that of plywood. The morphology was investigated by scanning electron microscopy (SEM).
\end{abstract}

Keywords: Areca fiber, composite, mechanical property, polyester

\section{Introduction}

Ecological awareness is forcing manufacturers to seek new resources which are eco-friendlier. In recent years, plant fibers have been getting 
substantial attention as alternatives of synthetic fiber reinforcements for applications like packaging, automobile, low-cost housing, and other constructions. The natural lignocellulosic fibers are capable to impart definite advantages to the composites such as low density, biodegradability and higher degree of flexibility during the manufacturing process. Currently natural fibers like, jute, coir, cotton, sisal, okra and other natural fibers have appealed the attention of technologists and scientists. It has been observed that the lignocellulosic fiber composites possess requisite physical, mechanical strength and other properties like good thermal properties with better electrical resistance (Rahman et al., 2018, Srinivasa et al., 2011).

Recently, widespread studies which have been ended on lignocellulosic fibers such as jute (Abdullah-Al-Kafi et al., 2006, De Albuquerque et al., 2000), sisal (Oksman et al., 2002), banana (Liu et al., 2009, Quintana et al., 2009), pineapple (George et al., 1998, Mishra et al., 2001) and oil palm empty fruit bunch fibers (Khalil et al. 2007, Rozman et al., 1999) have presented that the lignocellulosic fibers can be the potential and effective reinforcement in both thermoset and thermoplastic materials. According to Bledzki et al. (2002), and Wambua et al. (2003), lignocellulose fibers show numerous benefits over the synthetic fiber counterparts. Lignocellulose fibers have drawn huge attention due to their plentiful obtainability, renewable nature and lower cost. Lignocellulose fibers are able to deliver a high strength to weight ratio in plastic composite materials due to their low specific gravity, which is about $1.25-1.50 \mathrm{~g} / \mathrm{cm}^{3}$ compared to synthetic fibers, in particular, glass fiber which is about $2.6 \mathrm{~g} / \mathrm{cm}^{3}$. The production procedure of lignocellulose fibers also offers improved working condition than the synthetic fibers. On the other hand, skin irritation and respiratory diseases are initiated among workers from the trimming and mounting of glass fiber components (Sripaiboonkij et al., 2011).

Even though several studies on physico-mechanical properties of natural fiber reinforced composites have been carried out, only a few references are existing on areca fiber reinforced composites. Among the natural fiber reinforcing resources, areca seems to be a favorable material because it is plentifully obtainable, inexpensive and a very high potential perennial crop. It belongs to the species Areca Catechu L., under the family Palmecea and originated in the Malaya Peninsular, East India (Rajan et al., 2005). The husk of the areca constitutes about $60-80 \%$ of the total weight and volume of the fresh fruit. About $4 \mathrm{~cm}$ of filament length indicates that the areca husk fiber is too short compared to other bio-fibers. Both coarser and fine filaments are present in the fiber. The coarse ones are ten times coarser than the jute fibers and the finer are similar to jute fiber. The fiber could be used for making value added items like fluffy cushions, thick boards and non-woven fabrics (Arifulla et al., 2007). 
To develop the mechanical properties of the composites like strength, durability, stiffness, and reliability, it is essential to study the mechanical behavior of natural fiber composites. The mechanical behavior of a natural fiber-reinforced composite can be influenced by many factors, such as fiber length, strength, orientation, modulus and the interfacial bond strength between matrix and fiber. To achieve improved mechanical properties of the composites, a strong fiber-matrix interface bond is required. A good interfacial bond is mandatory for effective stress transfer from the matrix to the fiber whereby maximum utilization of the fiber strength in the composite is achieved. Most research reviewed indicates the effect of alkali treatment in improving fiber strength (Mohanty et al., 2000), fiber-matrix adhesion and the performance of the natural fiber composites (Kalia et al., 2009). Therefore, this study seeks to determine the tensile, flexural and impact properties of areca fiber reinforced polyester composites. A better understanding will help to develop productive end uses for areca fruit bunch, mitigating environmental problems from waste biomass while also developing an alternative material to wood.

\section{Methodology \\ Materials}

Polyester resin (Liquid SHCP 268 BQT), Hardener MEKP (Dimethyl ethyl ketone peroxide), Sodium Hydroxide and Acetic Acid, Mold (300 mm $\times 300 \mathrm{~mm} \times 6 \mathrm{~mm}$ ), Mold releasing agent and Mold releasing paper were purchased from local market, Dhaka. Areca fruits were obtained from a Firm House of Gazipur District, Bangladesh. The plywood of the same thickness was purchased from the renowned plywood producer of Bangladesh named 'Partex'.

\section{Fiber Extraction}

Firstly, areca fruits were dried under the sunlight for five days. Then the fruits were beaten by hammer for loosening the husks. The husks were manually separated from the nut by the use of dissecting needle. Areca husks were soaked in water for about five days. The soaking process allowed the separation and extraction of the fiber easily. Finally, the fibers were washed again with deionized water and dried at room temperature for about fifteen days. The dried fibers are designated as untreated fiber.

\section{Surface Modification}

The areca fibers were immersed in the solution of $2 \% \mathrm{NaOH}$ (on the sample weight) with maintaining the material liquor ratio of 1:40. Fibers were kept in this condition for 72 hours at room temperature. After that, the fibers 
were thoroughly washed in running water, then neutralized with $2 \%$ acetic acid solution. Finally, it was again washed in running water to remove any traces of acid sticking to it so that the $\mathrm{P}^{\mathrm{H}}$ of the fibers become neutral. Then they were dried at room temperature for 48 hours. The weight of the areca fibers was decreased by $10.2 \%$ after alkaline treatment.

\section{The Strength of Areca Fiber}

Most of the natural fibers show enhanced tensile strength than flexural strength. Areca fiber is one of such characteristic natural fiber materials. The strength must be confirmed in order to satisfy the requirements of application for any structural materials. Versatile tensile equipment (Houndsfield, UK) controlled by the computer is employed to conduct the strength test of areca fiber. $5 \mathrm{~N}$ load with a speed of $0.5 \mathrm{~mm} / \mathrm{min}$ was used in this experiment. Areca fiber was fixed in a paper support so that the fiber should not be twisted or broken during fixing into the jaws. This helps in maintaining a required gauge length of the specimen. The quick adhesive was used to fix the fiber in the fiber support. The gauge length of the test specimen was maintained at $20 \mathrm{~mm}$ in all the experiments.

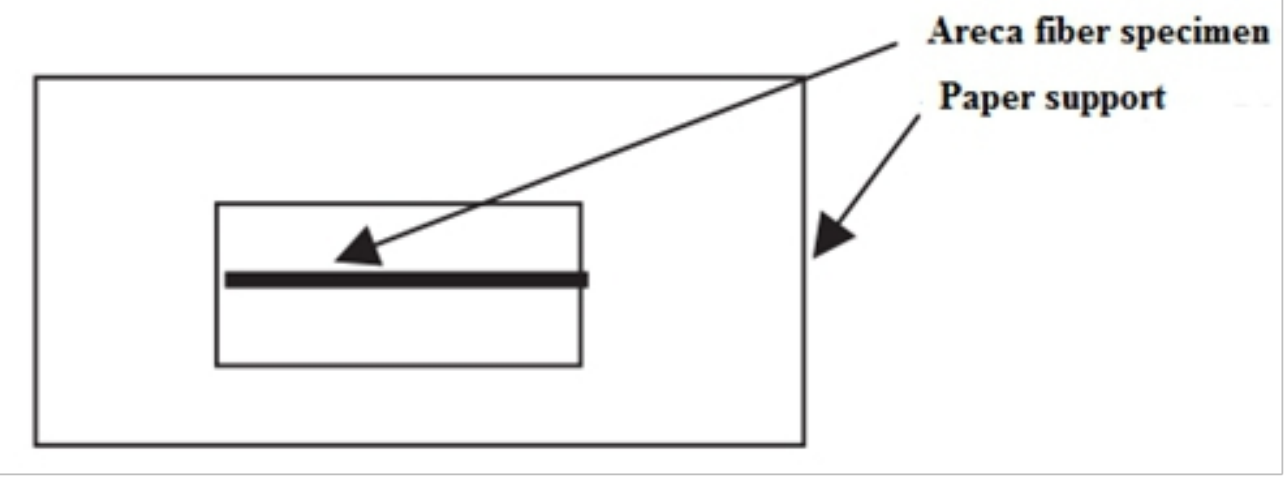

Figure 1: Specimen fixed on a paper support

Figure 1 shows the paper support used in the tensile test of the areca fiber. The specimen along with the paper support was transferred to the machine. Then a wing of the paper support was cut off so that the force developed in the machine will be acting totally on the fiber specimen. 10 samples were carried out to get the average values of the properties. Tensile strength, tensile modulus, and elongation at break were evaluated. In Figure 2 , the results show that the highest stress is $96.75 \mathrm{MPa}$ with $11.2 \%$ elongation at break for virgin fiber. Chemical treatment of areca fiber with $\mathrm{NaOH}$ shows that the treatment favorably increases the strength of the fibers. Maximum stress at fracture is found to be $117.25 \mathrm{MPa}$ with $15.6 \%$ elongation at break. 
The tensile modulus values were in the range of 1050-1140 MPa for both untreated and treated fibers.

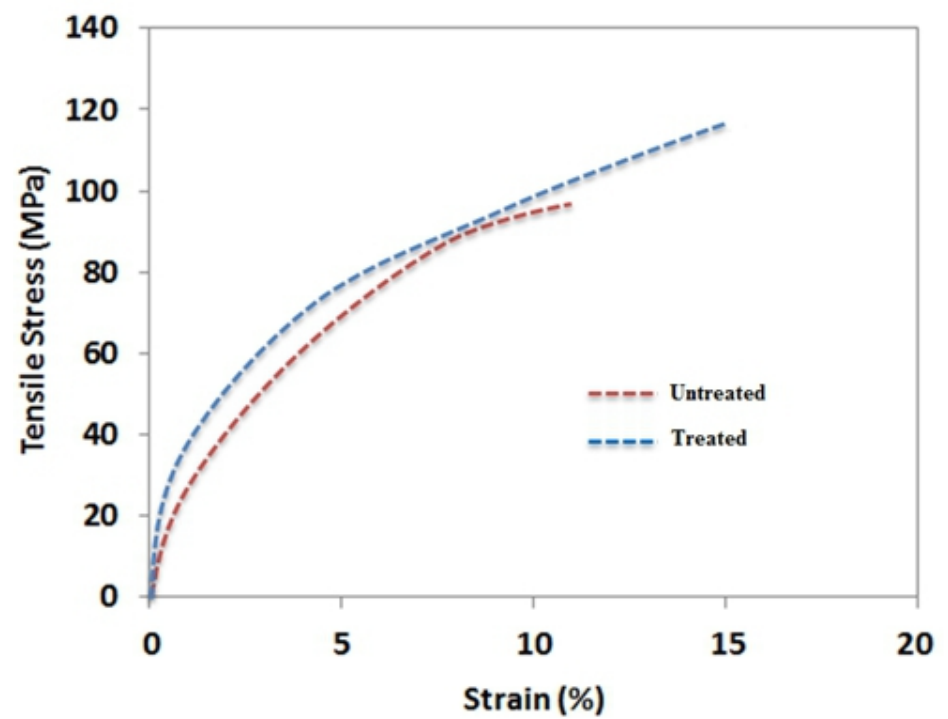

Figure 2: Stress-strain diagram for untreated and alkali treated areca fiber

\section{Fiber Preparation}

Both treated and untreated areca fibers were opened out by Shirley Analyzer. Fine and coarse fibers were separated by falling them into the delivery and waste box respectively. The coarse fibers were selected as reinforcing material.

\section{Preparation of Composites}

Fiber configuration and volume fraction are two important factors that affect the properties of the composite. In this work, the randomly distributed fibers were reinforced with polyester resin in two different weight proportions (5\% areca fiber with 95\% polyester resin and $10 \%$ areca fiber with $90 \%$ polyester resin on the basis of weight) to prepare the composites. This proportion remained same in the composite for both untreated and treated fibers. First, the mold ( $300 \mathrm{~mm} \times 300 \mathrm{~mm}$ x $6 \mathrm{~mm}$ ) was polished and then a mold-releasing agent (Polyvinyl alcohol) was applied on the surface to facilitate easy removal of the composite from the mold after curing. $50 \mathrm{gm}$ areca fiber and $2000 \mathrm{gm}$ polyester resin were measured by electrical balance respectively. Then 1\% (wt.\%) hardener MEKP thoroughly mixed into the polyester resin and stirring continued until the pink color is changed to grey. Then one-fourth mixture was poured into the mold and randomly distributed fibers were placed on the surface of the mixer to fill up the mold. The rest of the mixture was filled onto the fiber surface uniformly. The mold release paper 
(previously cut according to the size of mold) placed upon the mixture and manually a roller was driven to and fro for 5-7 minutes on the mold release paper to make the mixer uniform to prevent air bubble and then $10 \mathrm{~kg}$ weight placed on the mold release paper for 48 hours to cure the composite. In this way, four composite samples were made with varying the ratio of untreated and treated fiber.

\section{Mechanical Testing}

Tensile tests were carried out using a Universal Testing Machine (Hounsfield series S, model: H $50 \mathrm{KS}-0404$, UK) according to DIN 53455 standard method. The gauze length was $20 \mathrm{~mm}$ by maintaining the cross-head speed of $10 \mathrm{~mm} / \mathrm{min}$. The load capacity was $50 \mathrm{KN}$ and dimensions of the test specimen were $60 \mathrm{~mm} \times 15 \mathrm{~mm} \times 6 \mathrm{~mm}$. Flexural tests were evaluated according to DIN 53452 standard by means of the same testing machine at a cross-head speed of $10 \mathrm{~mm} / \mathrm{min}$ and span length was $40 \mathrm{~mm}$. The impact strength was examined using a pendulum type impact tester (MT-3016, Germany) according to DIN EN ISO 179 method in the flat wise, un-notched mode.

Samples were conditioned at $27^{\circ} \mathrm{C}$ and $55 \%$ R.H for several days before testing which is termed as dry state. The mechanical properties were also examined after the immersion of the samples for 10 days in deionized water which is termed as wet state. The final results were taken as the average values of the five samples.

\section{Water Uptake}

Composite samples $\left(20 \times 10 \times 6 \mathrm{~mm}^{3}\right)$ were immersed in a beaker containing deionized water at room temperature for 10 days. Before immersion in water, the specimens were dried properly and weighed. After definite periods of time, samples were withdrawn from the beaker and weighed. Water absorption was calculated by using the following formula: Water uptake $(\%)=\left[\left(\mathrm{W}_{\text {wet }}-\mathrm{W}_{\text {dry }}\right) / \mathrm{W}_{\text {dry }}\right] \times 100$, where $\mathrm{W}_{\text {dry }}$ and $\mathrm{W}_{\text {wet }}$ are the weight of the specimens before and after immersion.

\section{Scanning Electron Microscopic Analysis}

The composite samples were placed on an aluminum holder and sputtered with gold-platinum in a Hummer IV sputter coater. SEM micrographs were taken from scanning electron microscope at accelerating voltage of 10 and $15 \mathrm{KV}$. 


\section{Results and Discussion}

\section{Comparative Studies of the Mechanical Properties of the Composites}

The tensile, flexural and impact properties of the composites and plywood were evaluated and compared. The results are presented in Figure 37. Figure 3 and 4 indicates the tensile strength and tensile modulus of the composites respectively. The flexural strength and modulus of the composites are shown in Figure 5 and 6 respectively. The results of the impact strength in the dry and wet state are illustrated in Figure 7.

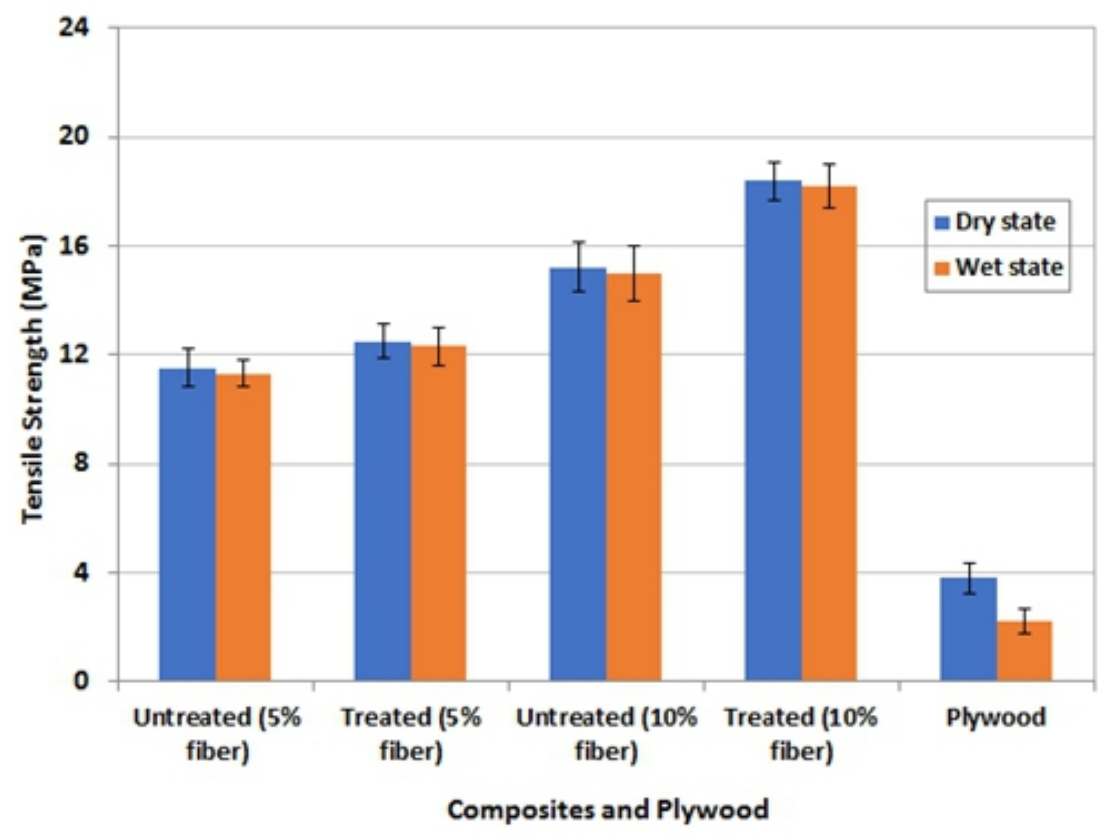

Figure 3: Tensile strength of areca-polyester composites and plywood in the dry and wet state

The TS, FS and IS of neat polyester were found to be $8.67 \mathrm{MPa}, 16.75$ $\mathrm{MPa}$ and $0.84 \mathrm{KJ} / \mathrm{m}^{2}$. From Figures 3-7, the TS, FS and IS of the untreated (5\% fiber) composites were found to be $11.53 \mathrm{MPa}, 21.25 \mathrm{MPa}$ and 1.12 $\mathrm{KJ} / \mathrm{m}^{2}$ respectively whereas that value for treated (5\% fiber) composites were $12.61 \mathrm{MPa}, 25.8 \mathrm{MPa}$ and $1.19 \mathrm{KJ} / \mathrm{m}^{2}$. The $\mathrm{TM}$ and $\mathrm{FM}$ values were $564 \mathrm{MPa}$, $1.5 \mathrm{GPa}$ for untreated (5\% fiber) and $636 \mathrm{MPa}, 1.9 \mathrm{GPa}$ for treated (5\% fiber) composites respectively. The TS, FS and IS of untreated (10\% fiber) composites were found to be $15.21 \mathrm{MPa}, 27.6 \mathrm{MPa}$ and $1.38 \mathrm{KJ} / \mathrm{m}^{2}$ respectively and that value for treated (10\% fiber) composites was $18.43 \mathrm{MPa}$, $30.7 \mathrm{MPa}$ and $1.62 \mathrm{KJ} / \mathrm{m}^{2}$ respectively. On the other hand, the TM and $\mathrm{FM}$ values were found to be $647 \mathrm{MPa}, 2.6 \mathrm{GPa}$ for $10 \%$ untreated and $756 \mathrm{MPa}$, $3.2 \mathrm{GPa}$ for $10 \%$ treated fiber composites respectively. 


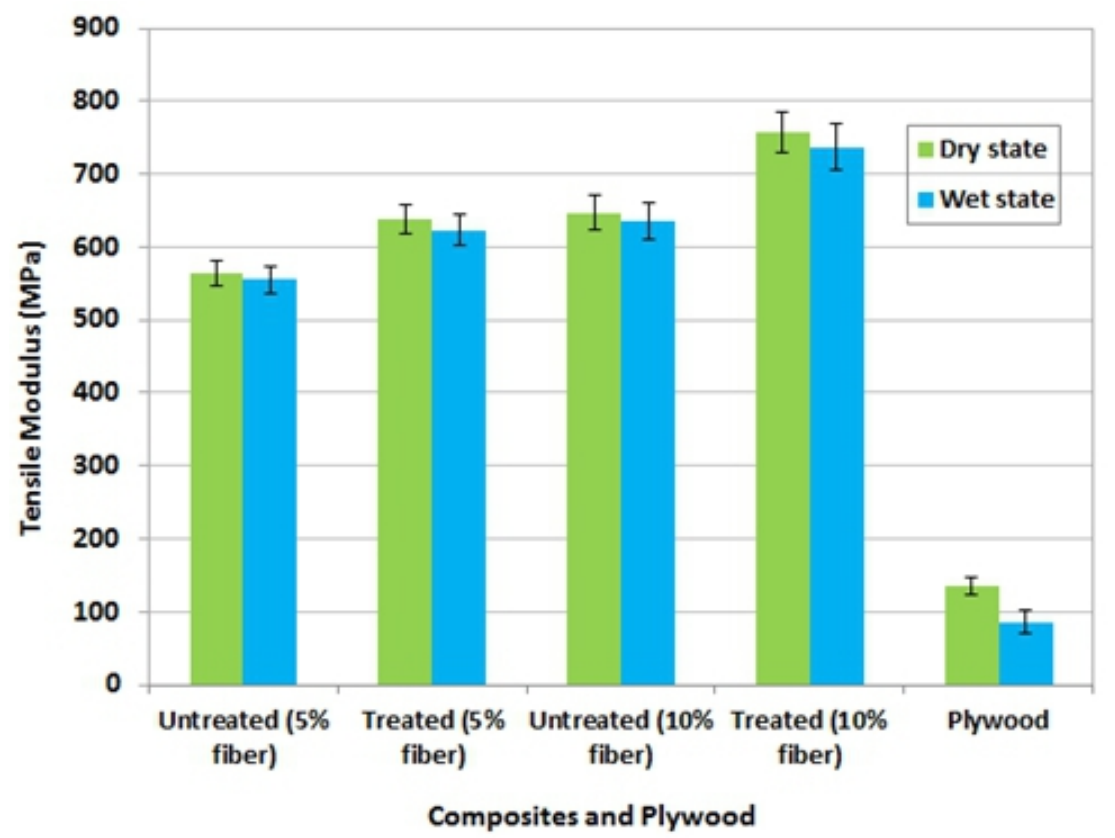

Figure 4: Tensile modulus of areca-polyester composites and plywood in the dry and wet state

From the figures, it was also found that the composites retained their original mechanical properties after 10 days of immersion of water, as the values were very much closer to dry state. The TS, FS and IS of untreated (5\% fiber) composites were improved 32.9, 26.8 and 33.3\% respectively compared to neat polyester. Again TS, FS and IS of untreated (10\% fiber) composites were improved $75.4,64.7$ and $76.1 \%$ respectively compared to neat polyester resin. Similarly, treated fiber reinforced composite possessed a significant improvement of TS, FS and IS compared to matrix polyester. The TS values were improved to 45.5 and $112.5 \%$ for treated 5 and $10 \%$ fiber composites respectively. On the other hand, FS values were enriched to 54 and $83.2 \%$ for treated 5 and $10 \%$ fiber composites respectively, while the IS values showed 52.3 and $92.8 \%$ development respectively. So, the results indicate that both types of fibers reinforced with polyester matrix successfully. Both untreated and treated composites gained a significant improvement in the mechanical properties. It was found that untreated fiber based composite showed relatively lesser TS, TM, FS, FM and IS and compared to treated fiber based composites. 


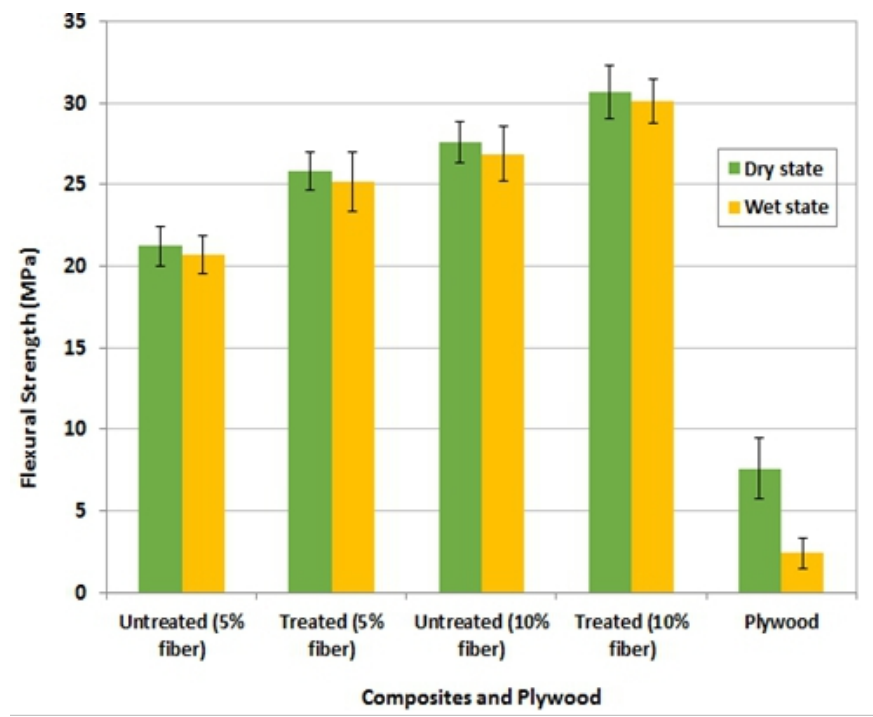

Figure 5: Flexural strength of areca-polyester composites and plywood in the dry and wet state

The TS, FS and IS values of plywood were 3.8 MPa, 7.6 MPa and 0.19 $\mathrm{KJ} / \mathrm{m}^{2}$ in the dry state and in the wet state, the values were $2.2 \mathrm{MPa}, 2.1 \mathrm{MPa}$ and $0.08 \mathrm{KJ} / \mathrm{m}^{2}$, which are much lower than the areca fiber composites. The TM values in the dry and wet state were found to be $135 \mathrm{MPa}$ and $85 \mathrm{MPa}$ respectively, whereas the FM values were $0.3 \mathrm{GPa}$ and $0.15 \mathrm{GPa}$ respectively. It was revealed that the treated (10\% fiber) composite found to be $21,11.2$ and $9.5 \%$ improvement of TS, FS and IS over the untreated (10\% fiber) composite respectively.

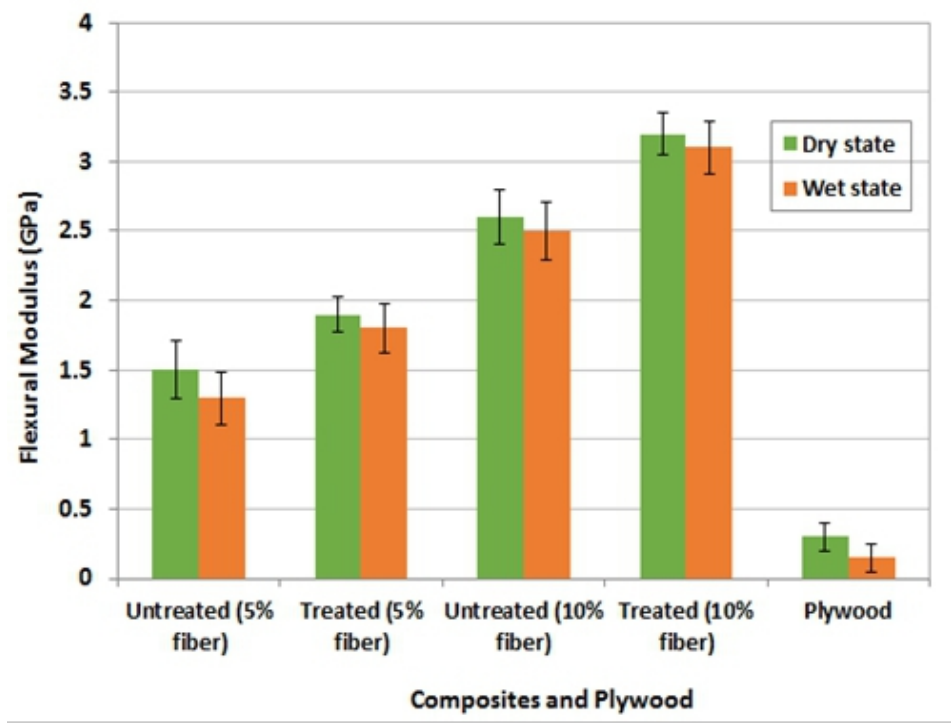

Figure 6: Flexural modulus of areca-polyester composites and plywood in the dry and wet state 
Alkali treatment improves the fiber-matrix adhesion due to the removal of dirty substances from the fiber and produces high-quality fibers. Alkali treatment also reduces fiber diameter, thereby increasing the aspect ratio. The development of rough surface topography and enhancement in aspect ratio offers better fiber-matrix interface adhesion and an increase in mechanical properties. Mercerization also increases surface roughness resulting in better mechanical interlocking between fiber and matrix (Hassan et al., 2011, Rahman et al., 2018).

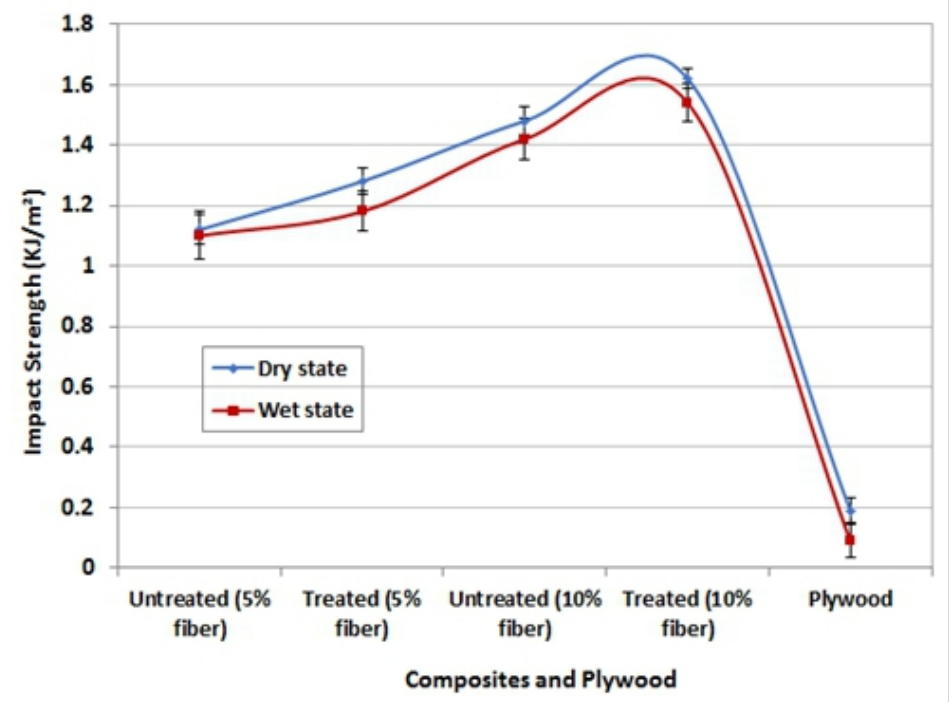

Figure 7: Charpy impact strength of the composites and plywood in the dry and wet state

\section{Water Uptake}

Water uptake decides the water-swelling performance of the composites. The results of water uptake (\%) of composites and plywood are shown in Figure 8 and 9 against the time (days) of the soaking in water. It was displayed that the untreated composites show considerably higher water absorption than that of treated composites. The water uptake values $(0.12-$ $0.35 \%$ ) of untreated (5\% fiber) composite at different soak time drops down to $(0.01-0.09 \%)$ for treated (5\% fiber) composite. Similarly, the water absorption values $(0.19-0.69 \%)$ of untreated ( $10 \%$ fiber) composite falls down to $(0.03-0.16 \%)$ for treated (10\% fiber) composite after 10 days of immersion. The water absorption by both untreated (5\% fiber and $10 \%$ fiber) samples was very fast within the initial 3 days. The absorption rate of treated composites was very slow and become static with time, whereas the untreated sample still continued to soak very slowly in the water up to 10 days. 


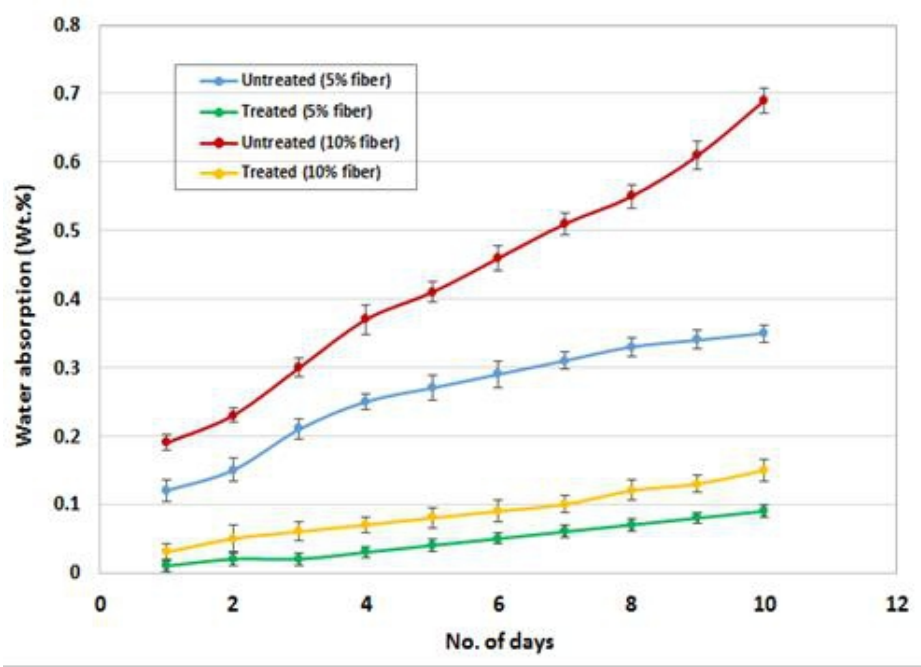

Figure 8: Water absorption\% of areca-polyester composites

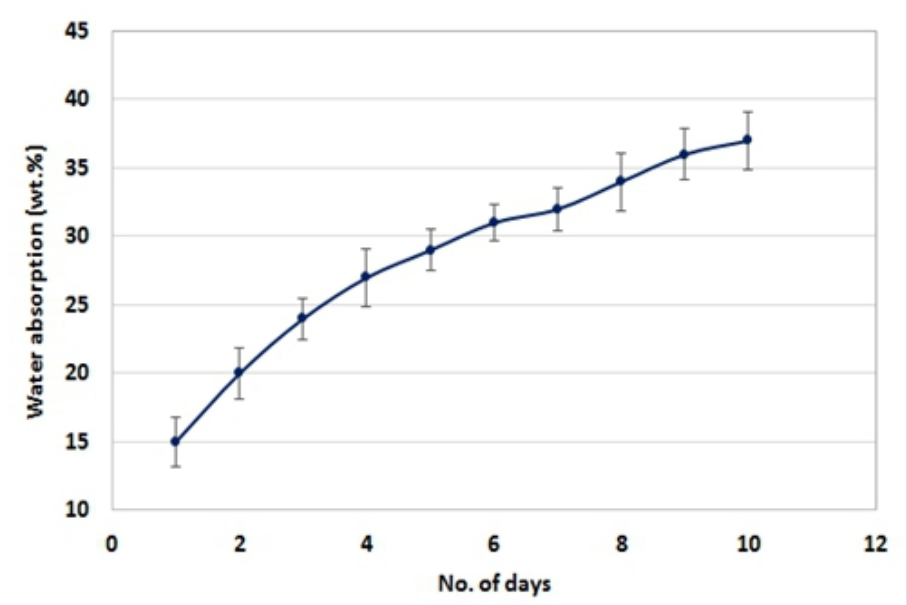

Figure 9: Water absorption\% of plywood

The untreated (5 and 10\% fiber) sample took water up to about 0.35 and $0.69 \%$ respectively, whereas that of the treated sample was about 0.09 and $0.15 \%$ respectively, which was well predictable and revealed that untreated composites absorb more water than treated composites. The reason behind the reduced absorption of water by the treated sample may be the void space of fiber filled by the polymer. Hydroxyl groups present in the cellulose form intermolecular hydrogen bonds with other cellulose molecules as well as with other hydrogen groups and increase moisture absorption. However, the groupings of long-chain cellulose molecules in the cell contain amorphous and crystalline regions. In the crystalline region, the hydroxyl groups of adjacent cellulose molecules are mutually bonded or cross-linked. For that reason, there 
are no sites to hold water within crystalline region is accessible for water absorption (Hassan et al., 2010; Sampathkumar et al., 2012).

On the other hand, Figure 9 indicates that the plywood samples absorbed more than $37 \%$ of water after 10 days immersion which was well estimated.

\section{Morphological Study}

To understand the adhesion between fiber and matrix, SEM studies were carried out. SEM images of the surfaces $(a, b)$ and fracture surfaces after tensile tests (c, d) are presented in figure 10. Only treated (10\% fiber) composites were selected for SEM analysis. From the figure, it is cleary seen that the surface is smooth and the pull-out of areca fiber is low and the bond between areca and polyester matrix is quite good. Fibers were incorporated properly inside the matrix and the agglomeration is not much high. Mercerization increases the surface roughness of fiber, as a result, better fibermatrix adhesion was originated. From the SEM image, it can be concluded that areca fibers and polyester matrix bonds are quite promising. In contrast, some short fibers of areca fiber edges are found in the composite which reduced the ultimate mechanical properties.
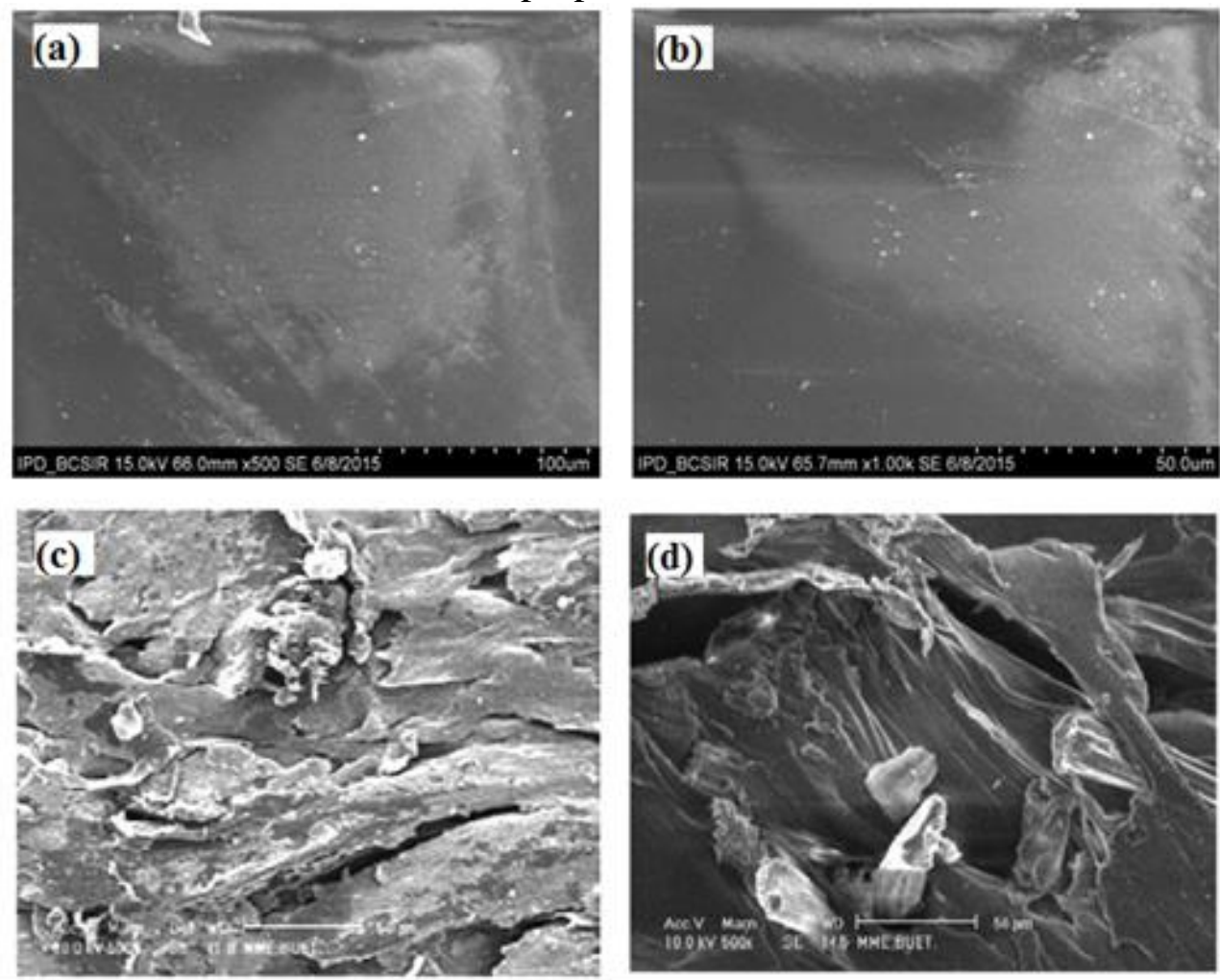

Figure 10: SEM image of the surface $(a, b)$ and tensile fracture surface $(c, d)$ of the treated (10\% fiber) composites 


\section{Conclusion}

Areca fiber reinforced polyester composites were manufactured efficaciously by the hand lay-up technique and physico-mechanical properties were evaluated. It can be concluded that the values of TS, FS and IS of the resulting alkali treated fiber composites were higher than that of virgin fiber composites. The investigation also showed that at $10 \%$ fiber content, the composites achieved the best mechanical properties. The TS, TM, FS, FM and IS were found to be $18.43 \mathrm{MPa}, 756 \mathrm{MPa}, 30.65 \mathrm{MPa}, 3.2 \mathrm{GPa}$ and $1.62 \mathrm{KJ} / \mathrm{m}^{2}$ for $10 \%$ treated fiber composites in the dry state respectively. In the wet state, these values were found 18.21 $\mathrm{MPa}, 737 \mathrm{MPa}, 30.12 \mathrm{MPa}, 3.1 \mathrm{GPa}$ and 1.54 $\mathrm{KJ} / \mathrm{m}^{2}$ respectively. The obtained results revealed that the composites retained their original mechanical properties in the wet state due to very little amount of water absorption. The water resistance behavior of composites was improved when composites were made with mercerized fiber. Finally, it had been observed that areca composites possessed sufficient physical and mechanical properties which can be used in diversified applications as the alternative of better quality plywood. SEM image showed the polyester and areca fiber was good in adhesion but interfacial affection can be further developed by increasing the fiber content and also by using coupling agent in the composite.

\section{References:}

1. Abdullah-Al-Kafi, Abedin, M., Beg, M., Pickering, K., \& Khan, M. A. (2006). Study on the mechanical properties of jute/glass fiberreinforced unsaturated polyester hybrid composites: effect of surface modification by ultraviolet radiation. Journal of Reinforced Plastics and Composites, 25(6), 575-588.

2. Arifulla, A., Goutham, N., Ravikumar, R., \& Santhosh Kumar, D. (2007). Mechanical characterization of areca composites-an experimental study. BE dissertation, Dept. of Mechanical Engineering, GM instiute of Technology, Davangere.

3. Bledzki, A. K., Sperber, V., \& Faruk, O. (2002). Natural and Wood Fibre Reinforcement in Polymers (Vol. 13): Smithers Rapra Publishing.

4. De Albuquerque, A., Joseph, K., de Carvalho, L. H., \& d'Almeida, J. R. M. (2000). Effect of wettability and ageing conditions on the physical and mechanical properties of uniaxially oriented jute-rovingreinforced polyester composites. Composites Science and Technology, $60(6), 833-844$.

5. George, J., Sreekala, M., Thomas, S., Bhagawan, S., \& Neelakantan, N. (1998). Stress relaxation behavior of short pineapple fiber 
reinforced polyethylene composites. Journal of Reinforced Plastics and Composites, 17(7), 651-672.

6. Hassan, M. M., Wagner, M. H., Zaman, H., \& Khan, M. A. (2010). Physico-mechanical performance of hybrid betel nut (Areca catechu) short fiber/seaweed polypropylene composite. Journal of Natural Fibers, 7(3), 165-177.

7. Hassan, M. M., Wagner, M. H., Zaman, H. U., \& Khan, M. A. (2011). Study on the performance of hybrid jute/betel nut fiber reinforced polypropylene composites. Journal of Adhesion Science and Technology, 25(6-7), 615-626.

8. Kalia, S., Kaith, B., \& Kaur, I. (2009). Pretreatments of natural fibers and their application as reinforcing material in polymer compositesa review. Polymer Engineering \& Science, 49(7), 1253-1272.

9. Khalil, H. A., Hanida, S., Kang, C., \& Fuaad, N. N. (2007). Agrohybrid composite: the effects on mechanical and physical properties of oil palm fiber (EFB)/glass hybrid reinforced polyester composites. Journal of Reinforced Plastics and Composites, 26(2), 203-218.

10. Liu, H., Wu, Q., \& Zhang, Q. (2009). Preparation and properties of banana fiber-reinforced composites based on high density polyethylene (HDPE)/Nylon-6 blends. Bioresource Technology, 100(23), 6088-6097.

11. Mishra, S., Misra, M., Tripathy, S., Nayak, S., \& Mohanty, A. (2001). Potentiality of pineapple leaf fibre as reinforcement in PALF-polyester composite: Surface modification and mechanical performance. Journal of Reinforced Plastics and Composites, 20(4), 321-334.

12. Mohanty, A., Misra, M., \& Hinrichsen, G. (2000). Biofibres, biodegradable polymers and biocomposites: an overview. Macromolecular Materials and Engineering, 276(1), 1-24.

13. Oksman, K., Wallström, L., Berglund, L. A., \& Filho, R. D. T. (2002). Morphology and mechanical properties of unidirectional sisal-epoxy composites. Journal of Applied Polymer Science, 84(13), 2358-2365.

14. Quintana, G., Velasquez, J., Betancourt, S., \& Ganan, P. (2009). Binderless fiberboard from steam exploded banana bunch. Industrial Crops and Products, 29(1), 60-66.

15. Rahman, A.N.M.M., Alimuzzaman, S., Khan, R. A., Khan, M. E., \& Hoque, S. N. (2018). Fabrication, Mechanical Characterization and Interfacial Properties of Okra Fiber Reinforced Polypropylene Composites. International Journal of Engineering Materials and Manufacture, 3(1), 18-31.

16. Rajan, A., Kurup, J. G., \& Abraham, T. E. (2005). Biosoftening of arecanut fiber for value added products. Biochemical Engineering Journal, 25(3), 237-242. 
17. Rozman, H., Tay, G., Kumar, R., Abubakar, A., Ismail, H., \& Ishak, Z. M. (1999). Polypropylene hybrid composites: a preliminary study on the use of glass and coconut fiber as reinforcements in polypropylene composites. Polymer-Plastics Technology and Engineering, 38(5), 997-1011.

18. Sampathkumar, D., Punyamurthy, R., Bennehalli, B., \& Venkateshappa, S. C. (2012). Effect of esterification on moisture absorption of single areca fiber. International Journal of Agriculture Sciences, 4(4), 227.

19. Srinivasa, C., Arifulla, A., Goutham, N., Santhosh, T., Jaeethendra, H., Ravikumar, R., . . . Ashish, J. (2011). Static bending and impact behaviour of areca fibers composites. Materials \& Design, 32(4), 2469-2475.

20. Sripaiboonkij, P., Sripaiboonkij, N., Phanprasit, W., \& Jaakkola, M. (2011). Respiratory and skin health among glass microfiber production workers: a cross-sectional study. Occup Environ Med, 68(Suppl 1), A64-A64.

21. Wambua, P., Ivens, J., \& Verpoest, I. (2003). Natural fibres: can they replace glass in fibre reinforced plastics? Composites Science and Technology, 63(9), 1259-1264. 